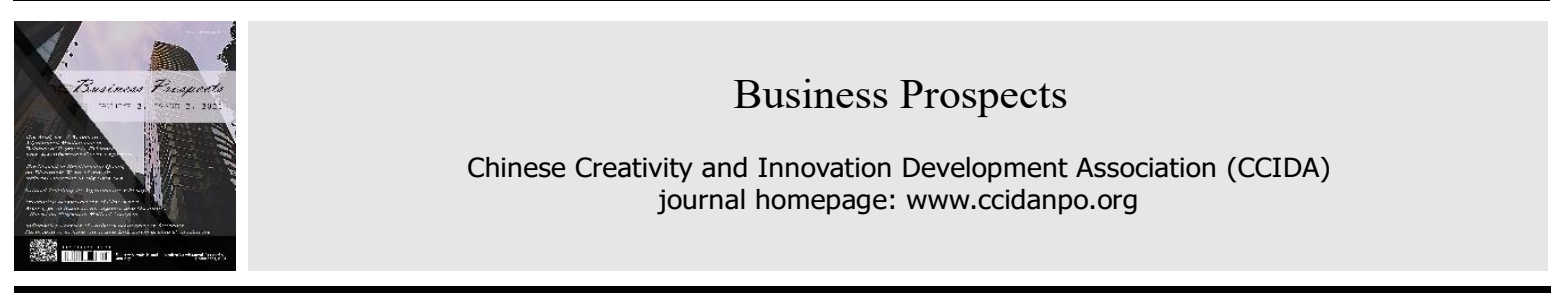

https://doi.org/10.52288/bp.27089851.2021.12.08

\title{
Situation of Logistics Management Students Participating in Innovation and Entrepreneurship Activities
}

\author{
Qi Yuan ${ }^{1}$ and Meng Chen ${ }^{2, *}$ \\ ${ }^{1}$ School of Management, Xiamen University Tan Kah Kee College \\ ${ }^{2}$ Associate professor of School of Management, Xiamen University Tan Kah Kee College \\ * Correspondence: chenmeng@xujc.com.
}

Received: 2021.10.14; Accepted: 2021.11.04; Published: 2021.12.01

\begin{abstract}
With the development of social economy, innovation and entrepreneurship have made great contributions to society. In order to actively respond to policies and keep pace with the times, colleges and universities encourage students to actively participate in innovation and entrepreneurship competitions. This article starts from the questionnaire situation of logistics management students participating in innovation and entrepreneurship activities in a school, analyzes the reasons that promote and hinder students from participating in innovation and entrepreneurship activities, and puts forward further suggestions based on the current situation and resources.
\end{abstract}

Keywords: Logistics Management; Innovation and Entrepreneurial Activities Situation

\section{Foreword}

Innovation and entrepreneurship are not only the requirement of the times, but also the inevitable requirement of building an innovative country (Song and Wang, 2020). Students are the leaders of the times and the main force in the construction of the country. Only when students have an awareness of innovation can they inject innovative vitality into the country. At present, innovation and entrepreneurship education is in a period of reform and development. In order to explore the development of innovation and entrepreneurship education in colleges and universities under the guidance of national policies, the article is based on the actual situation of logistics management major of Xiamen University Tan Kah Kee College. First, the team launches an actual survey of students' participation in innovation and entrepreneurship activities. Next, innovation entrepreneurship education development issues are summarized. Finally, targeted suggestions are proposed.

\section{The Background and Significance of College Students' Participation in Innovation and Entrepreneurship Activities}

\subsection{Policy Background}

In recent years, the state has strongly supported colleges and universities to carry out innovation and entrepreneurship education and related activities. As early as 1998, the Ministry of Education issued the "Action Plan for the Promotion of Education in the 21st Century", proposing to cultivate and encourage a group of highlevel entrepreneurial talents to start entrepreneurship; "Opinions on Issues Related to System Reform" pointed out that college students are encouraged to apply for ourselves and entrepreneurship (Yang, 2021); in 2007, the General Office of the Ministry of Education issued the "Course Requirements for College Students' Career Development and Employment Guidance Courses" to incorporate entrepreneurship education into the teaching plan and set indicators; In 2010, the Ministry of Education issued the "Opinions on Vigorously Promoting Innovation and Entrepreneurship Education in Institutions of Higher Learning and College Students' 
Independent Entrepreneurship Work" and pointed out that students are the main group of innovation and entrepreneurship, and universities of all levels across the country are required to carry out innovation and entrepreneurship education in a unified manner; In February 2012, the Ministry of Education pointed out in the "Notice on Doing a Good Job in the Implementation of the" Undergraduate Teaching Project "National College Student Innovation and Entrepreneurship Training Program" that it will promote the National Innovation and Entrepreneurship Program with fund subsidies; In May 2015, the Ministry of Education issued the "Implementation Opinions on Deepening the Reform of Innovation and Entrepreneurship Education in Colleges and Universities", which proposed to upgrade innovation and entrepreneurship education to a national strategy and reform the long-term key sticking points and outstanding issues ${ }^{1}$; In 2018, the State Council issued the "Opinions on Promoting the High-quality Development of Innovation and Entrepreneurship and Creating an Upgraded Version of innovation and entrepreneurship", it require universities to configure entrepreneurial mentors and incorporate innovation and entrepreneurship into compulsory courses. All these provide a solid foundation for further promoting innovation and entrepreneurship education.

\subsection{Value Meaning}

Innovative and entrepreneurship activities are a form of boosting innovation and entrepreneurship education, and have great significance to the society, students, and universities.

\subsection{Easing the Employment Pressure}

The emergence of new entrepreneurial motivation under the innovative entrepreneurship education model has alleviated the employment difficulties caused by the mismatch between the expanding employment population and the job market. Graduates no longer passively seek positions that are inconsistent with their dreams and their majors, but instead create positions based on their own characteristics and advantages to achieve multi-faceted employment (Yang, 2017). In addition, innovation and entrepreneurship projects add impetus to industrial development, increase jobs for the society, facilitate people's lives, and make the country prosperous and social progress.

\subsubsection{Creating Self-worth}

Innovation and entrepreneurship activities aim to cultivate innovative talents that meet the needs of the country and adapt to social development, and provide students with a platform for trial and error then realize their dreams. Competitions that are highly relevant to the characteristics of various majors can promote the effective integration of professional students' theoretical study and practical operation, absorb and learn other unrelated professional knowledge and competition experience, exercise students' innovative and entrepreneurial thinking, and improve hands-on, scientific research and project management ability. It can also look for selfworth in the collision of campus culture and entrepreneurial culture to gain a sense of honor and accomplishment.

\subsubsection{Increasing the Comprehensive Advantages of Colleges and Universities}

Recently, the state has advocated the development of applied universities and the delivery of comprehensive talents to the society. Every year, in terms of enrollment, the employment rate of colleges and universities has become a factor affecting enrollment. Colleges and universities have fully implemented innovation and entrepreneurship activities, but there are some gaps in the number of participants, the quality of the projects, and the status of awards. This has become a measure of the success of the transformation to an application-oriented university. The implementation and management of innovation and innovation education in various universities are uneven, and some campus do not have sufficient teaching staff and lack a complete education system (Zhang, 2021). Therefore, strengthening the education and activities of innovation and entrepreneurship plays an important role in enhancing the comprehensive advantages of colleges and universities.

\footnotetext{
${ }^{1}$ Implementation Opinions of the General Office of the State Council on Deepening the Reform of Innovation and Entrepreneurship Education in Colleges and Universities (2015-05-13).
} 


\section{The Basic Situation of the Survey of Logistics Management Students from the Xiamen University Tan Kah Kee College Participating in Innovation and Entrepreneurship Activities}

The logistics management major is one of the first-class majors in the Xiamen University Tan Kah Kee College. Focus on training applied and integrated logistics talents with logistics management, operation, planning and design capabilities who can engage in production, warehousing, procurement, trade, freight forwarding policy formulation and management in trading companies, logistics companies, and manufacturing companies. This major always attaches great importance to innovation and entrepreneurship activities, and promotes students to cultivate innovative and entrepreneurial thinking in various ways.

In order to understand the specific situation of logistics management students participating in innovation and innovation, and improve and perfect the innovation and innovation education of this major, the research team released an online questionnaire to students majoring in logistics management in grades 2018, 2019, 2020, and 2021 on September 30, 2021 and learn about the participation in innovation and entrepreneurship activities. As of October 6th, 122 valid questionnaires have been received, including 31 for the 2018 level, 27 for the 2019 level, 20 for the 2020 level, and 44 for the 2021 level.

\subsection{More Participants in BC Type Events}

Of the 122 people surveyed, 62 have not participated in innovation and entrepreneurship activities, and 60 have participated in innovation and entrepreneurship activities. In the data that have participated in the competition, the students who have participated in the $\mathrm{C}$ category competition accounted for $33.61 \%$ of the total number, the B category accounted for $31.15 \%$, the A category accounted for $21.31 \%$, and the D category accounted for $11.48 \%$.

There are more participants in $\mathrm{BC}$ events. This is because most of the competitions related to logistics management belong to the $\mathrm{BC}$ category, and the $\mathrm{BC}$ category is less difficult than the $\mathrm{A}$ category, and compared with the D category, the gold content is higher, which makes students more willing to participate in the $\mathrm{BC}$ category.

\subsection{More Participants in Comprehensive and Logistics Professional Competitions}

Among the A-type events, $84.62 \%$ have participated in the "Internet +" college student innovation and entrepreneurship competition, $34.62 \%$ have participated in the "Challenge Cup" extracurricular academic science and technology competition, and 57.69\% have participated in the "Challenge Cup" entrepreneurial plan competition.

In category B events, $68.42 \%$ have participated in the National University logistics Design Competition; 47.37\% have participated in the e-commerce "Innovation, Creativity and Entrepreneurship" Challenge, 39.47\% have participated in the National English Contest for College Students, and 28.95\% have participated in the Mathematical Modeling competition of College Students, 23.68\% have participated in the National College Student Market Research and Analysis Competition, $18.42 \%$ have participated in the China Innovation and Entrepreneurship Competition, $15.79 \%$ have participated in the "FLTRP Cup" National English Speech Competition, $10.53 \%$ have participated in the Energy Conservation and Emission Reduction Social Practice and Technology Competition, and $5.26 \%$ participated in the National College Student Career Planning Competition.

In category $\mathrm{C}$ events, $73.71 \%$ have participated in the National Logistics Simulation Design Competition, $65.85 \%$ have participated in the National Supply Chain Competition, $34.15 \%$ have participated in the Chain Warfare Smart Supply Chain Innovation and Entrepreneurship Challenge, 19.51\% have participated in the "FLTRP Cup" National English Writing Competition, 14.63\% have participated in the National English Reading Competition, $19.51 \%$ have participated in the Cross-Strait University Students Vocational Skills Competition, 2.44\% have participated in the National Supply Chain Management Vocational Skills Competition, and 0\% have participated in the Fujian University Students Cultural Innovation and Creative Design Competition.

From the above data, there are more participants about the logistics and comprehensive competitions in the $\mathrm{ABC}$ competitions. This is because the characteristics of logistics management students with logistics professional knowledge and abilities meet the requirements of logistics competitions and can give full play to their strengths; And comprehensive competitions are suitable for students of all majors to participate, so most students choose logistics and comprehensive competitions. 


\subsection{The Types of Innovation and Entrepreneurship Competitions That Students Participate in Are Concentrated}

For students who have participated in innovation and entrepreneurship activities, $71.67 \%$ prefer innovation, $70 \%$ prefer entrepreneurship, $46.67 \%$ prefer knowledge, $31.67 \%$ prefer design, $16.67 \%$ prefer art, $6.67 \%$ prefer mechanical engineering, and $8.33 \%$ prefer to participate computer-type competition. For students who have not participated but are interested, $64.15 \%$ of those who choose innovation and entrepreneurship, $41.51 \%$ of design, $35.85 \%$ of knowledge, $22.64 \%$ of art, $3.77 \%$ of computer, and $1.89 \%$ of mechanical engineering.

From the data, students who have participated or have not participated but are not inclined to choose arts, mechanical engineering, and computer activities. This is because art, mechanical engineering, and computer type have high professional requirements, and are more suitable for students of this major to participate. Moreover, logistics management students are inconvenient in finding other professional teachers. It is not ruled out that some logistics management students have this aspect Specialties.

\subsection{Competitions, Topics, and Essays Have a Higher Degree of Choice}

In the choice of innovative and entrepreneurial forms, competitions accounted for $77.36 \%$, topics accounted for $66.04 \%$, papers accounted for $47.17 \%$, and inventions accounted for $20.75 \%$. For students who have never participated but are willing to choose the form of innovation and entrepreneurship, competitions accounted for $86.67 \%$, papers accounted for $60 \%$, topics accounted for $43.33 \%$, and inventions accounted for $16.67 \%$.

From the data, both students who have participated and those who have not participated in the innovation and entrepreneurship activities in the form of selection competitions, essays, and topics are preferred. These three forms are generally available for students to participate and complete. The invention category requires more research and practical skills for students. In addition, students majoring in logistics management do not have this expertise, so the form of competitions, essays, and topics are more suitable for students majoring in logistics management.

\section{Summary of the Logistics Management Students of Xiamen University Tan Kah Kee College Participating in Innovation and Entrepreneurship Activities}

\subsection{Positive Factors}

\subsubsection{Students Are Generally Willing to Participate in Innovation and Entrepreneurship Activities}

In the questionnaire data, 60 people have participated in the competition and 62 people have not participated in the competition. Among the unattended groups, 53 people have the intention to participate and 9 people have no intention to participate.

The number of participants and willingness prove that most students are willing to participate in innovation and entrepreneurship activities, but there are some factors that fail to make some students put their ideas into action.

\subsubsection{Students Use Innovation and Entrepreneurship Activities as a Platform to Enrich Themselves}

In the investigation of the reasons for participating in innovation and entrepreneurship activities, $80 \%$ were exercise ability, $66.67 \%$ were broadened horizons and rich resumes, $48.33 \%$ experienced atmosphere, $43.33 \%$ met friends, $41.67 \%$ received academic credit, and $30 \%$ earned bonuses. $16.7 \%$ of those who try at will, and $10 \%$ of those who realize their dreams.

Combined with the data, it can be known that the participating students want to enrich themselves through innovation and entrepreneurship activities, exercise their competition, hands-on, and communication skills, meet friends from different majors and learn with them, feel the strong competitive atmosphere, and go out of the campus to carry out field research to broaden their horizons. They also want to enrich their resume through competitions and prove themselves with academic credit and bonuses.

\subsubsection{Students Use Their Professional Knowledge Well}

From the perspective of students' preference for logistics competitions, logistics management students want to test the solidity of their professional theoretical knowledge and the ability to combine theory with practical operations through the competition. They want to consolidate and apply knowledge and create new methods in practice. 


\subsection{Hindering Factors}

\subsubsection{The Time of Students to Participate in Activities Is Limited}

Most of the students who have not participated are in the 2021 and 2018 grades. The freshmen who have just entered the campus have no chance to participate in the activities; and the senior students do not have time to participate in the activities due to work internships, postgraduate exams, and civil service exam preparations. Participants are mostly sophomores and seniors. This means that students can only participate in a limited number of competitions during the four years of college.

\subsubsection{The Proportion of Men and Women Participating in Activities Is Not Balanced}

The number of students who have participated in innovation and entrepreneurship and those who have not participated but are interested in is that the number of girls is greater than that of boys. Excluding the proportion of major gender, it shows that boys are less motivated to participate in activities. However, an appropriate combination of male and female members in a team is beneficial to the team cooperation. Lack of male members will affect the team and the game to a certain extent.

\subsubsection{The Type Activities that Students Participate in Is Single}

It can be seen from situations of more participants in logistics competitions that most logistics management students only choose to participate in professional-related competitions, which is not conducive to the comprehensive enrichment of their knowledge system and the growth of comprehensive students.

\section{Summary of Problems and Countermeasures for Further Implementation of Innovation and Entrepreneurship Activities}

\subsection{Summary of Innovation and Entrepreneurship Activities and Education Issues}

\subsubsection{Students Are Not Clear about the Information on Innovation and Entrepreneurship Activities}

Among the reasons why students do not participate in activities, $66.67 \%$ of them are not familiar with innovation and entrepreneurship activities. Students are not clear about the detail, gold content, and competition period of innovation and entrepreneurship activities, which directly leads to students not being able to participate in innovation and entrepreneurship activities. Therefore, students' ignorance of innovation and entrepreneurship information has become an urgent problem to be solved.

\subsubsection{The Ability of Students Is Insufficient}

Innovation and entrepreneurship activities require students to have bold and implementable innovative ideas, which forces students who are willing to try but do not have the ability to innovate to give up participating in activities. Moreover, most of the students have insufficient experience in entrepreneurship and lack of understanding of the market and consumer psychology, which makes them not have the advantage. The above is the reason why students are afraid of competition and do not participate in the competition.

\subsubsection{Lack of Professional and Practical Guidance}

The lack of teacher's guidance makes students' competition works immature and unreasonable. Professional and responsible instructors, however, can make students have the confidence to participate in activities.

\subsubsection{Students Assume that Participation in Activities Affects Learning}

Some students think that participating in innovation and entrepreneurship activities will affect their learning. This is because students participating in the activities need spend leisure time for activity preparation and competitions except daily professional courses. If they cannot coordinate activities and study time, they may affect their learning.

\subsubsection{The Lack of Teammates and the Single Professionalism of Members Has Become an Obstacle}

Students know only a limited number of classmates, so they have ideas but lack of teammates also hinder 
students' enthusiasm for participating in innovation and entrepreneurship activities; The major of most team members are the same, so the problem of unclear task division often occurs when compared with comprehensive teams. There is no competitive advantage.

\subsection{Countermeasures and Suggestions}

In response to the deficiencies found in the above survey and research, in order to better carry out innovation and entrepreneurship education in logistics management, the article puts forward the following suggestions:

\subsubsection{The Side of Students}

First, the initiative of students is the prerequisite for everything. Before promoting students to participate in innovation and entrepreneurship activities in various ways, students need to have their own interest in the activities and willingness to participate. Students should take the initiative to learn about innovation and entrepreneurship activities through various methods such as inquiries from teachers, organizations, classmates, and campus websites; Secondly, built a solid foundation and expanded knowledge. Students should strengthen the comprehensive and in-depth study of their professional knowledge, and learn other professional knowledge through independent study or elective courses in preparation for participating in multiple types of activities. In addition, students should try more exchange experiences and ideas with surrounding or participating students and find inspiration in failure or success.

\subsubsection{The Side of Teachers}

First, for classroom teaching, offer more innovative and entrepreneurial elective courses that students are interested in and add case teaching analysis, laboratory simulation teaching, social practice and other methods in the classroom to inspire students' creativity and train students' innovative ability (Dong, 2021); Secondly, try to provide activity guidance for each group of participating teams and provide them with references and suggestions in the competition; In addition, provide personalized customization for students and recommend students who are interested in participating in activities in after-school guidance that suit their abilities and ideas race.

\subsubsection{The Aspect of Organization}

First, in response to students' low grasp of information on innovation and entrepreneurship activities, the logistics association and the science and technology center responsible for the event should increase the publicity of the dual innovation activities, and organize instructors and previous award-winning students to hold competition presentations according to the time of the event. In the presentation, exchange experience with each other, arrange guidance for students who are interested in participating in the competition (Liu, 2019); Secondly, since the team members have a single major and the students have ideas but lack teammates, the school student union should set up an online and offline team platform to facilitate communication between people in various majors who are interested in teaming to achieve complementary advantages and according to disciplines.

\subsubsection{The Aspect of Major}

First, gather outstanding teachers of logistics management, set up an innovation and entrepreneurship guidance team, and conduct regular training for teachers to improve the level of guidance; Secondly, implement teaching plans and activities in accordance with national policies, and increase publicity of innovation and entrepreneurship for students or even provide professional guidance and advice.

\section{Concluding Remarks}

The promotion of innovation and entrepreneurship requires the proactiveness of students, the professional guidance of teachers, the joint efforts of the state and the government. This article starts from the participation of students majoring in logistics management in Xiamen University Tan Kah Kee College in innovation and entrepreneurship, analyzes their development and puts forward targeted suggestions to form an innovation and entrepreneurship culture in the school, achieve full participation, and make students to keep up with the times to finally become comprehensive and innovative talents. 
Acknowledgments: 2021 National College Student Innovation and Entrepreneurship Training Project: Exploration of the integration and development of first-class majors and innovation and entrepreneurship education under the new situation.

\section{References}

1. Dong, W. (2021). Analysis of Innovation and Entrepreneurship Education in Undergraduate Colleges. Investment and Cooperation, 9: 177-178.

2. Implementation Opinions of the General Office of the State Council on Deepening the Reform of Innovation and Entrepreneurship Education in Colleges and Universities (2015-05-13).

3. Liu, C. Y. (2019). Research on the Status Quo and Improvement Measures of Local University Graduate Students Participating in Innovation and Entrepreneurship Competitions. Education Teaching Forum, 49: 90-91.

4. Song, Z. H., \& Wang, Z. B. (2020). The Evolution and Development Trend of China's Innovation and Entrepreneurship Education Ecosystem. China Higher Education, 2: 38-39+54.

5. Yang, D. (2021). The Trajectory, Mechanism and Reflection of the Policy Changes of Innovation and Entrepreneurship Education in Universities in China. University Education Management, 5: 90-104.

6. Yang, J. (2017). The Role of "Internet +" Competition in the Reform of Double Innovation Education in Colleges and Universities. Education Teaching Forum, 25: 100-102.

7. Zhang, C. (2021). How to Break Through the Reform Bottleneck of Innovation and Entrepreneurship Education in Colleges and Universities. Chinese Businessmen, 4: 56-57.

(Editor: Yuxin Ke) 